Nevşehir Bilim ve Teknoloji Dergisi Cilt 5(1) 35-45 2016

DOI: 10.17100/nevbiltek.03470

URL: http://dx.doi.org/10.17100/nevbiltek.03470

\title{
Taşınabilir Çeviklik Ölçüm Sisteminin Tasarımı ve Gerçekleştirilmesi
}

\author{
Uğur FİDAN ${ }^{1}$, Mehmet Yıldız ${ }^{2}$,Muhammet Ali USER ${ }^{3, *}$ \\ ${ }^{1}$ Afyon Kocatepe Üniversitesi, Mühendislik Fakültesi, Biyomedikal Mühendisliği Bölümü,Afyonkarahisar \\ ${ }^{2}$ Afyon Kocatepe Üniversitesi, Beden Eğitimi Spor Yüksek Okulu, Afyonkarahisar \\ ${ }^{3}$ Nevşehir Hacıbektaş Veli Üniversitesi,Hacıbektaş Veli Meslek Yüksekokulu, Nevşehir
}

$\ddot{O} \mathbf{z}$

Tüm antrenör ve sporcuların temel gayesi, en yüksek performansa ulaşmaktır. Çeviklik, takım ve raket sporlarının sportif başarısında belirleyici faktör olarak yer almaktadır. En az oranda hız ve kontrol kaybıyla etkili yön değiştirme becerisi olarak tanımlanan çeviklik literatürde planlı ve reaktif olmak üzere iki kategoride ele alınmaktadır. Reaktif çeviklik testi içinde görsel stratejileri, bilişsel faaliyetleri ve takım sporlarıyla ilişkili çeviklik özelliklerini büyük oranda içine alacak şekilde yeniden ele alınması gerekmektedir. Bu çalışmanın amacı takım sporlarına yönelik içinde birçok uyaranın olduğu mobil kullanıma uygun yeni bir reaktif test ölçüm sisteminin tasarımı ve gerçekleştirilmesi olarak belirlenmiştir. Bu çalışmada mevcut çeviklik ölçüm cihazlarından farklı olarak telemetri sistemi ile kablolamanın önüne geçilmiş ve yön değiştirme sayısı da 2 katına çıkarılmıştır. Ayrıca çok sık arıza yapan sıçrama matları yerine optik yansımadan yararlanarak daha kullanışlı bir ölçüm sistemi geliştirilmiştir.

Anahtar Kelimeler: Çeviklik, Çeviklik Testleri, Spor, Performans

\section{Design and Implementation of Portable Agility Measurement System}

\begin{abstract}
The main purpose of all coaches and athletes is to achieve the highest performance. Agility plays an important role in success of team and racket sports. In literature, defined as ability to change direction effectively with minimum rate of loss speed and control, agility is categorized as planned and reactive. Reactive agility test will need be reconsidered as into the agility associated with visual strategies, cognitive abilities and team sports greatly. The purpose of this study is determined as performing and designing a new reactive measurement system included a lot of stimulus related to team sports. In this study, wiring is prevented by utilizing telemetry system as a different from existing agility measurement devices and the number of direction change is increased to 2 times. It has also been developed a more useful measurement system by utilizing the optical reflection instead of splash mats that makes often failure.
\end{abstract}

Keywords: Agility , Agility Tests, Sports, Performance

* e-mail: muhammet.user@nevsehir.edu.tr 
Fidan U., Yıldız M., User MA.

1. Giriş

Spor; insanların beden ve ruh sağlıklarını koruyabilmeleri ya da fizikî performanslarını üst düzeye çıkararak yarışmak için yaptıkları hareketler bütünüdür. Tüm antrenör ve sporcuların temel gayesi, en yüksek performansa ulaşmaktır. Oyuncunun dayanıklılık, kuvvet, sürat, çeviklik, esneklik ve beceri gibi motor özelliklerin gelişimi spor dalına özgü yapılan çalışmalar ve antrenmanlarla sağlanabilir [1]. Bilim ve teknolojideki gelişim her alanda olduğu gibi sportif performans gelişimine de katkı sağlamaktadır. Bu amaçla her geçen gün yeni yöntemler ve teknikler ortaya çıkmaktadır.

Çeviklik, takım ve raket sporlarının sportif başarısında belirleyici faktör olarak yer almaktadır. Çeviklik, en az oranda hız ve kontrol kaybıyla etkili yön değiştirme becerisi olarak tanımlanır [2,3]. Buna göre ani yavaşlamayı, yön değiştirmeyi ve tekrar hızlanmayı kapsar [4]. Çevikliği ölçmek ve geliştirmek için başlangıcı, sonu ve nerde yön değiştirmelerin belli olduğu önceden bilinen kapalı beceri testleri kullanılmaktadır [18]. Son yıllarda çevikliği etkileyen bilişsel faaliyetlerinde çalışmaların içine dâhil edildiği görülmektedir. Bilişsel faaliyetlerin işin içine girdiği bu tip testler literatürde reaktif çeviklik testleri olarak anılmaktadır. Bu testlerin temelinde 1 şık, video, gerçek kişi veya bilgisayarla sporcuya komut verip sporcunun bu komutlara göre testi bitirmesi beklenmektedir. [5].

Literatür taraması yapıldığında çevikliğin planlı ve reaktif olmak üzere iki kategoride ele alındığı görülmektedir [4]. Planlı çeviklik hareketleri; başlangıç ve sonunun nerelerde yön değiştirmelerin olduğunun bilindiği kapalı beceri çalışmalarından oluşmaktadır [6]. Reaktif çeviklik ise motorik özelliklerle beraber içinde algısal ve karar verme becerilerinin bulunduğu bilişsel özellikleri de ölçmeye çalışan açık beceri çalışmaları olarak tanımlanmıştır $[7,8]$.

Reaktif çeviklik testleri uyarının bilgisayar [9,10], 1şık [9,11], video [4,12,13] ve gerçek kişiler $[14,15]$ tarafından verildiği ve katılımcıların buralardan gelen uyaranlara göre tepki verdiği ve içinde yer değiştirmelerin olduğu testlerden oluşmaktadır.

Hertel [9] ve Lima [10] çalışmalarında reaktif çevikliği ölmek için bilgisayar sistemli cybexreactor cihazını kullanmışlardır. Bu sistemde katılımcının karşında bir bilgisayar ve üzerinde daireler bulunan bir mat bulunmaktadır. Sporcu matı ve üzerindeki dairelerin görüntüsünü bilgisayar sisteminde görebilmektedir. Sporcu bilgisayar tarafindan gösterilen daire üzerinde durur. Daha sonra bilgisayar ekranda muhtelif daireleri yansıtır ve katılımcının bu dairelere hızla hareket etmesi istenir. Testin içeriğine bakıldığında daha çok dövüş sporları, eskrim vb. spor branşı için uygun olduğu görülmektedir.

Yapılan reaktif çeviklik çalışmalarına bakıldığında genellikle laboratuvar şartlarında gerçekleştirilen ve saha kullanıma uygun olmayan sabit bilgisayarlı sistemlerden oluştuğu görülmektedir. Bununla beraber kapalı beceri çeviklik testlerinin kapladığı alandan (Uzunluk 5m-10m ve Genişlik 5m10m) çok daha küçük alanda reaktif yön değiştirme yapıldığından futbol ve basketbol gibi büyük alanlarda ortaya konan yön değiştirmelere uygun görülmemektedir. Katılımcıya sadece bir uyaran verildiği ve verilecek uyarının çıkış yerlerinin birbirine çok yakın olmasından dolayı fiksasyon, dikkati yöneltme ve odaklanma gibi görsel stratejiler ve bilgi toplama, analiz etme ve doğru uyarana yönelme gibi bilişsel faaliyetleri çok az içermektedir. Ayrıca verilecek olan uyarı seçeneği sadece iki tane olduğundan katılımcı daha test başlangıcında \%50 hızlı tahmin etme şansına sahiptir. Sonuç olarak gerek 
video gerekse gerçek kişilerce sergilenen hareketlerin tek içerikli olması ve katılımcının da sadece savunmaya yönelik tahmin ve önsezilerini ölçmesi çevikliğin bilişsel faaliyet alanlarını daraltmaktadır.

Tüm bu veriler ışığında, reaktif çeviklik testinin içinde görsel stratejileri, bilişsel faaliyetleri ve takım sporlarıyla ilişkili çeviklik özelliklerini büyük oranda içine alacak şekilde yeniden ele alınması gerekmektedir. Bu çalışmanın amacı takım sporlarına yönelik içinde birçok uyaranın olduğu mobil kullanıma uygun yeni bir reaktif test ölçüm sisteminin tasarımı ve gerçekleştirilmesi olarak belirlenmiştir.

\section{Materyal ve Metot}

Çeviklik, vücudun bütününün veya belirli parçasının yapılması gereken ideal açısal değerlere getirilmesidir. Bu nedenledir ki çevikliği ortaya çıkan bir uyarım, pozisyon, durum veya olay sonucu, organizmanın daha önceden öğrendiği veya öğrenmediği hareketleri koordine ederek aniden yerine getirebilme özelliği şeklinde tanımlayabiliriz [16]. Çeviklik (Şekil 1) karar verme mekanizmaları ve yön değiştirme gibi psikolojik ve fiziksel iki ana bileşenden oluşur [17]

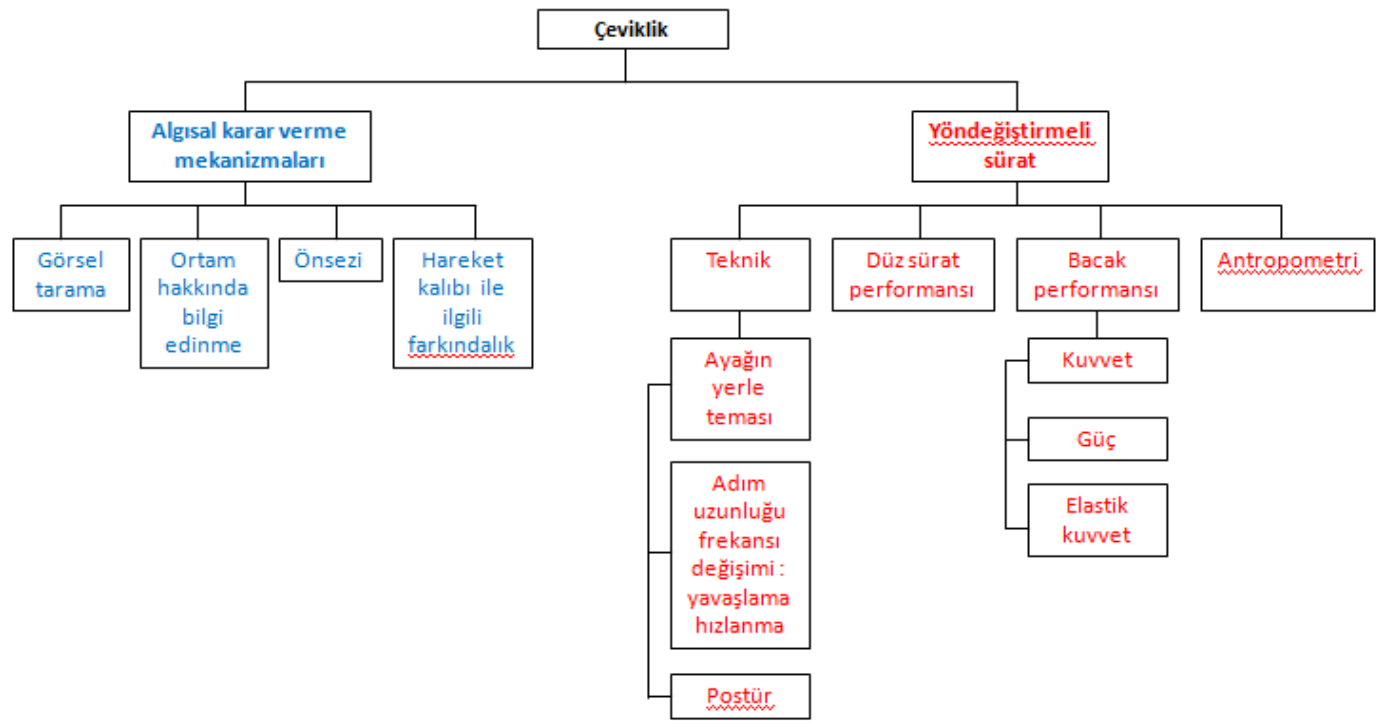

Şekil 1. Çeviklik Bileşenleri[3]

\section{1 Çeviklik Testleri}

Çeviklik performansının ölçülmesi, gelişimin planlanması açısından önemlidir. Antrenör ve sporcuların kolaylıkla yapabileceği bazı saha testleri geliştirilmiştir. Bu testlerin ortak özelliği sahada uygulanabilir olması ve basit birkaç ekipmanla ölçümün yapılabilmesidir. Tablo 1'de sporda yaygın olarak kullanılan çeviklik test çeşitleri görülmektedir. [1,18]

Tablo 1. Sporda Kullanılan Ceviklik Testleri

\begin{tabular}{|l|}
\hline Reaksiyon Testi \\
\hline Pro-Agility Çeviklik Testi \\
\hline Illinois Çeviklik Testi \\
\hline 505 Çeviklik Testi \\
\hline T Testi \\
\hline
\end{tabular}


Söz konusu testlerin kullanım alanları branşlara ve var olan ekipman ve saha yeterliliğine göre değişiklikler göstermektedir[3]. Tablo 2'de çeviklik antrenman çeşitlerinin hangi gruba ve hangi alıştırma türlerine kullanılması gerektiği görülmektedir. [8-12]

Tablo 2. Çeviklik Antrenman Çeşitleri[8-9-12]

\begin{tabular}{|c|c|c|}
\hline Antrenman grubu & Açıklama & Alıştırma türleri \\
\hline $\begin{array}{l}\text { Yöndeğiştirme Tekniğine } \\
\text { Yönelik Alıştırmalar| }\end{array}$ & $\begin{array}{l}\text { Yöndeğiştirme tekniğini geliştirmeye } \\
\text { ve pekiştirmeye yönelik alışturmalar }\end{array}$ & $\begin{array}{l}\text { Öne, geriye ve yanlara adım çalışmalan, } \\
\text { Düşük hızda yapılan hızlanma, yavaşlama ve } \\
\text { yöndeğiştirme alıştırmalan }\end{array}$ \\
\hline Kapalı Beceri Alışturmalan & $\begin{array}{l}\text { Mesafesi ve yönü önceden belirlenmiş } \\
\text { kapalı beceri alıştırmalan }\end{array}$ & $\begin{array}{l}\text { Yüksek hızda geriye ve yanlara koşu ve kayma } \\
\text { alş̧turmalan, } \\
\text { Yöndeğiştirmeli sürat alışturmalan }\end{array}$ \\
\hline Çabukluk Alışturmalan & $\begin{array}{l}\text { Uzuvların frekansının geliştirilmesine } \\
\text { yönelik kapalı beceri alıştırmalanı }\end{array}$ & $\begin{array}{l}\text { Merdiven, çubuk, çember, huni veya engel üzeri } \\
\text { yüksek frekansta uygulanan çabukluk } \\
\text { alışturmalan }\end{array}$ \\
\hline $\begin{array}{l}\text { Reaktif } \\
\text { Antrenmanı }\end{array}$ & $\begin{array}{l}\text { Rakip veya bir nesne ile ilgili bilgi } \\
\text { edinme üzerine kurulu açık beceri } \\
\text { alışturmalan }\end{array}$ & $\begin{array}{l}\text { Ayna ve gölge alş̧turmalan, } \\
\text { Yakalama ve kaçma oyunlanı }\end{array}$ \\
\hline
\end{tabular}

\subsection{Taşınabilir Çeviklik Ölçüm Sistemi}

Çeviklik ölçüm sistemi (Şekil 2) sporcunun hareketleri belirlemek için kapı diye adlandırılmış algılayıcılar, ana kontrol ünitesi ve PC yazılımı olmak 3 temel bölümden oluşmaktadır.Kapı olarak kullanılacak sensör sayısı ise 1 adet start sensörü, 4 adet temel kapılar olmak üzere 5 adet kullanılmıştır.Şekilde $\mathrm{n}$ adet kapı yazılmasının sebebi özellikle hızlanma ölçümünde kapı sayısının isteğe göre değiştirilmesidir.

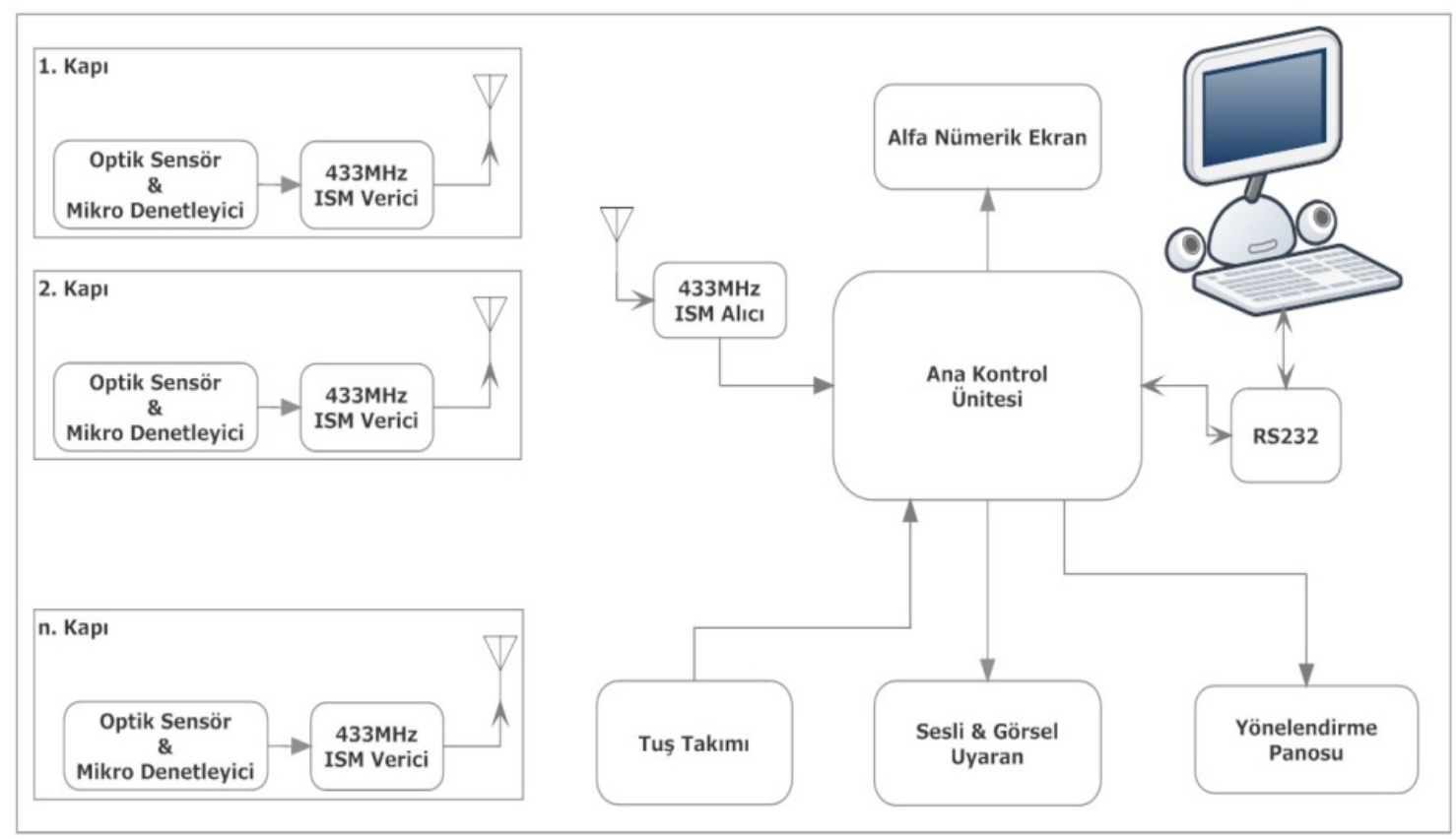

Şekil 2. Çeviklik Ölçüm Sistemi Blok Diyagramı

Kap1; algılayıcı, mikro denetleyici ve RF verici olmak üzere 3 kısımdan oluşmaktadır. Algılayıcı olarak $15^{\circ}$ e algılama açısı ve $2 \mathrm{~ms}$ tepki süresine sahip Sharp marka MZ80 cisimden yansımalı optik sensörü kullanılmıştır. Merkezi işlem birimi olarak Microchip firmasının RISC mimarisine sahip 16 F877 
denetleyicisi kullanılmıştır. Kapı ile ana kontrol ünitesi arasındaki iletişim Kısa Mesafe Erişimli Telsiz Cihazlarının Temel Standartları ile Kurma ve Kullanma Esasları Hakkında Yönetmeliği’nin (TGM-STK001) 433-434MHz ISM bandı ile ilgili bölümünü kapsayacak şekilde tasarlanmış ATX-34S ve NRX-34U radyo frekans modülleri ile sağlanmıştır. Alıcı verici yaklaşık 50 metreye kadar yayın yapabilmektedir.

Ana kontrol ünitesi; tuş takımı, RF alıcı, mikro denetleyici 18F6720, mikro denetleyici yazılımı (Şekil 3) alfa nümerik ekran, yönlendirme panosu, sesli \& görsel uyaran ve RS232 haberleşme portundan oluşmaktadır. Ana kontrol ünitesi hem PC hem de tek başına kullanılabilmek üzere tasarlanmıştır. Tuş takımı ile kullanıcının cihazı istenen çalışma moduna alabilmesi sağlanmıştır. Cihaz ile alınan ölçüm sonuçları 4x20 alfa numerik ekranda görüntülenirken aynı zamanda 9,6Kb/s hızında kişisel bilgisayara aktarılmaktadır. Ana kontrol ünitesi üzerindeki ölçümler kapılardan gelen bilgiye göre yapılmaktadır. Kapılardan gelen veriler NRX-34U alıcı ile mikro denetleyiciye gelmektedir. Cihazın çalışması, ana kontrol ünitesinde çift RS232 çıkışa sahip 18F6720 denetleyici ile sağlanmaktadır. Cihaz üzerinde kronometre, reaksiyon, sıçrama ve hızlanma olmak üzere 4 farklı çalışma modu vardır.

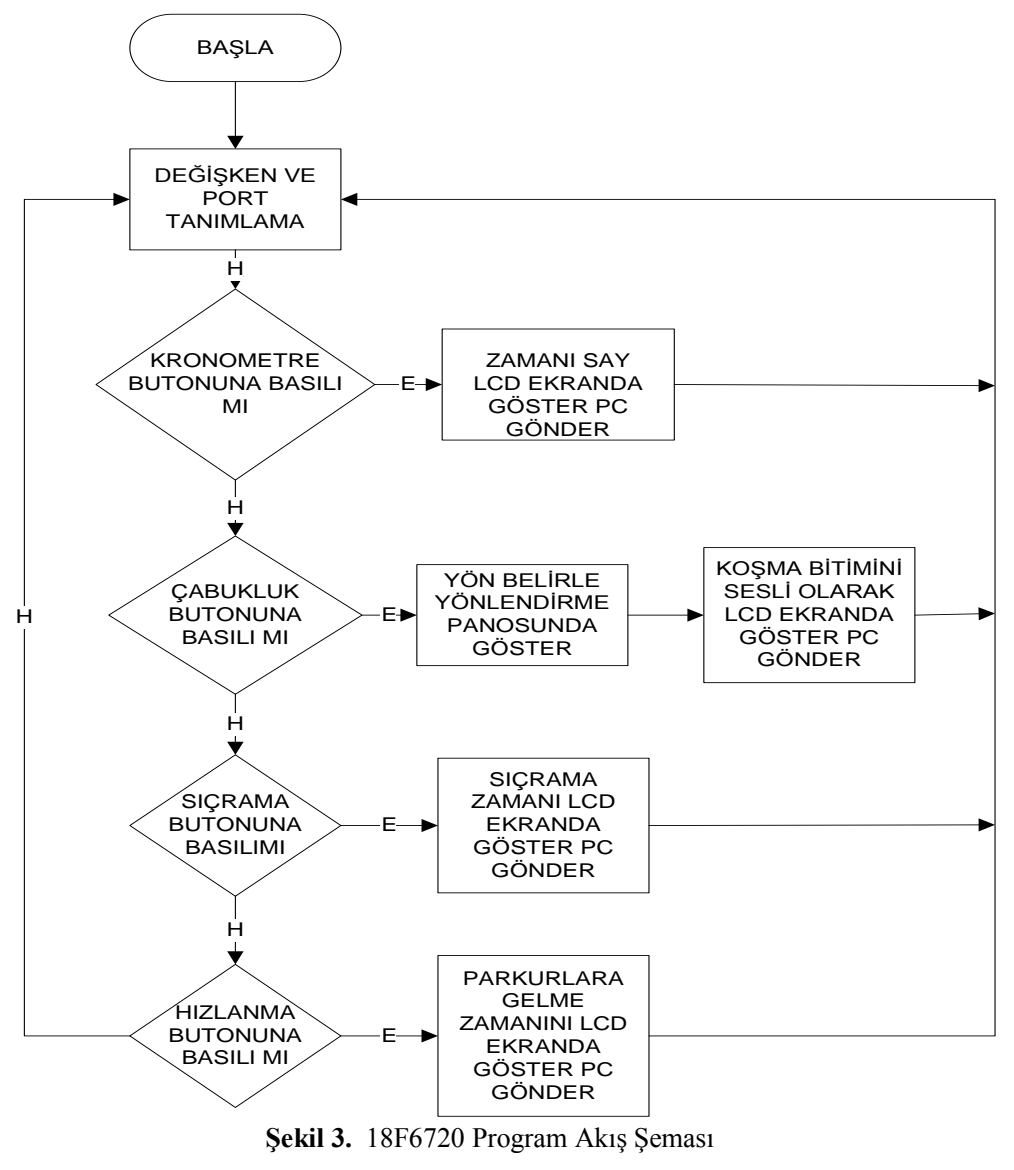

Şekil 4'de PC yazılımı akış şeması görülmektedir. Ana kontrol ile PC arasındaki bağlantı (M2Pc) RS232 haberleşme portu üzerinden sağlanmaktadır. M2Pc bağlantı sağlandıktan sonra hesaplamaların yapılması ve veri tabanına kayıtlarının yapılabilmesi için sporcunun adı soyadı, tarih, saat, kilo ve boy verilerinin kullanıcı tarafından girilmesi istenir. Daha sonra kullanıcıdan çalışama modunu (Hız \& Patlama kuvveti, Hız \& akselerasyon, çeviklik, reaksiyon ve anaerobik güç) seçmesi istenir. Sporcu sesli ve görsel uyarlara göre teste başlar. Test boyunca sporcunun performansı kapılardan gelen 
Fidan U., Yıldız M., User MA.

bilgilere göre değerlendirilir. Cihazdan gelen ölçüm verileri Eşitlik 1'de kullanılarak sporcunun hız ve patlama kuvveti menüsünden sıçrama yüksekliği ölçülmüştür.

$\mathrm{h}=9,81 \times t^{2} \div 8$

$\mathrm{h}=$ Sıçrama yüksekliği $(\mathrm{cm})$

$\mathrm{t}=$ Havada kalma süresi (sn)

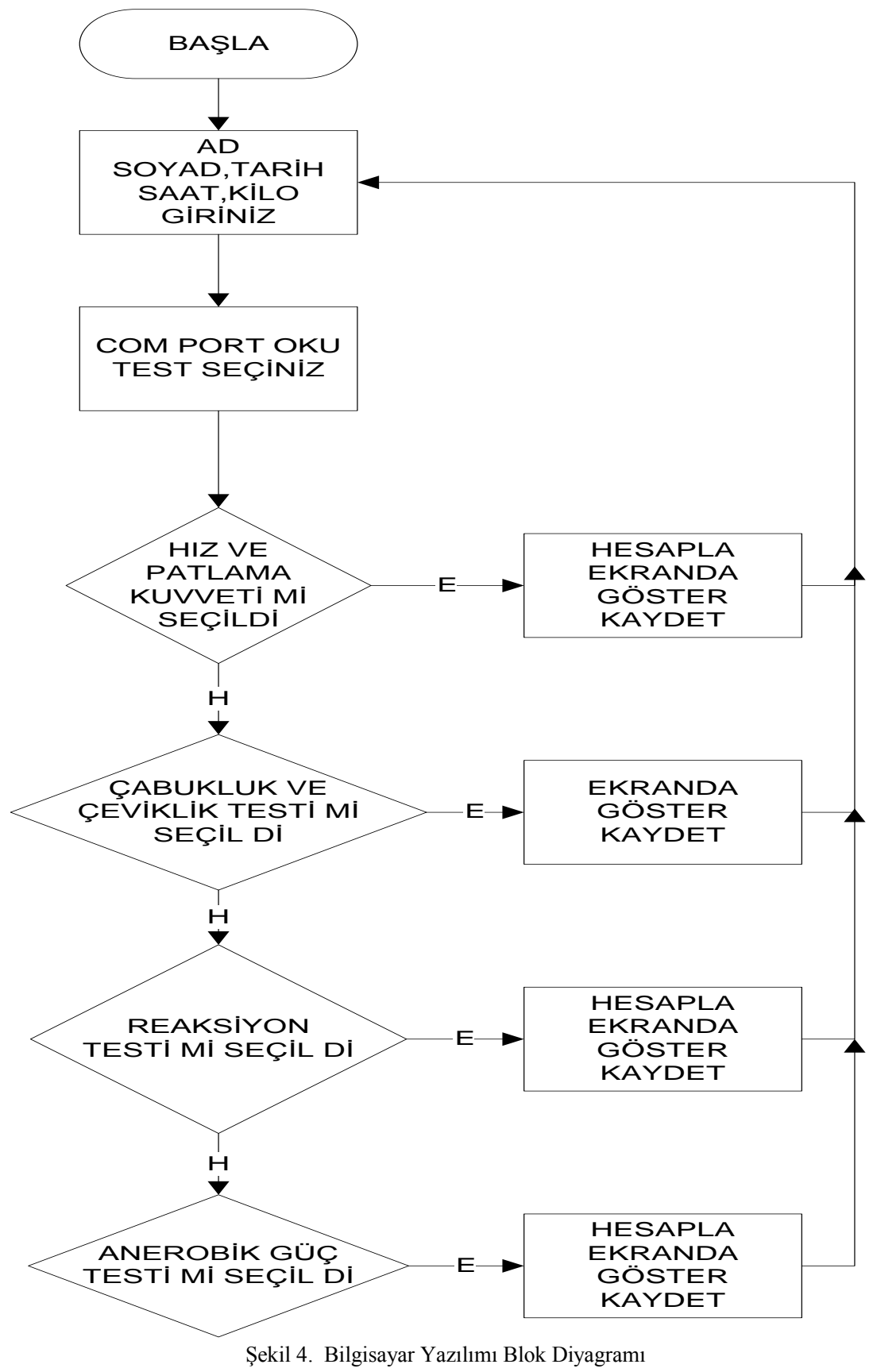

Sporcunun çeviklik ölçümü olan 505 testi, illinois testi, T testi ve Ajax mekik koşusu gibi çeviklik testleri bilgisayar tarafından testi bitirme zamanı ölçülerek ortaya konulmuştur. Reaksiyon süresi bir uyarıcının sunulması ile söz konusu uyarıcıya kas tepkisi verilmesi arasında geçen süreyi 
göstermektedir. Sporcunun anerobik güç kapasitesi Eşitlik 2’deki denklem ile ölçülmektedir. Tüm ölçüm sonuçları eş zamanlı olarak ekranda görüntülendiği gibi daha sonra analiz edilebilmesi için veri tabanına kayit edilmektedir.

$P=(60,7 \times h)+(45,3 \times m)-2055$

$\mathrm{P}=$ Anaerobik güç $(\mathrm{W})$

$\mathrm{h}=$ Siçrama yüksekliği $(\mathrm{cm})$

$\mathrm{m}=$ Vücut ağırlı̆̆ $(\mathrm{kg})$

\section{Bulgular ve Tartışma}

Şekil 5'de gerçekleştirilen çevik ölçüm sisteminin ana kontrol ünitesi ve sporcunun tepki sürelerini ölçmek için kullanılan kapı ünitesi görülmektedir.

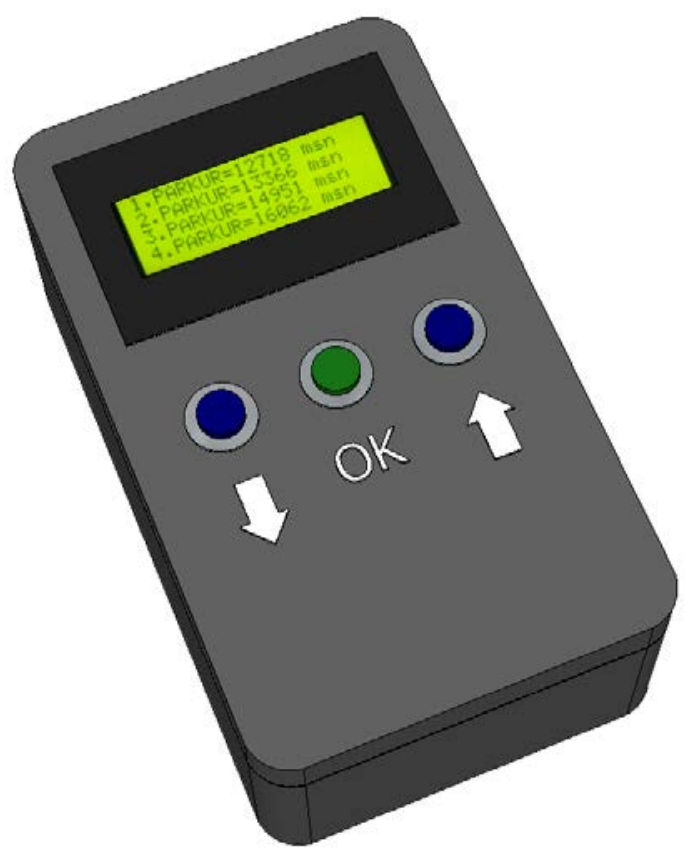

a) Ana Kontrol Ünitesi

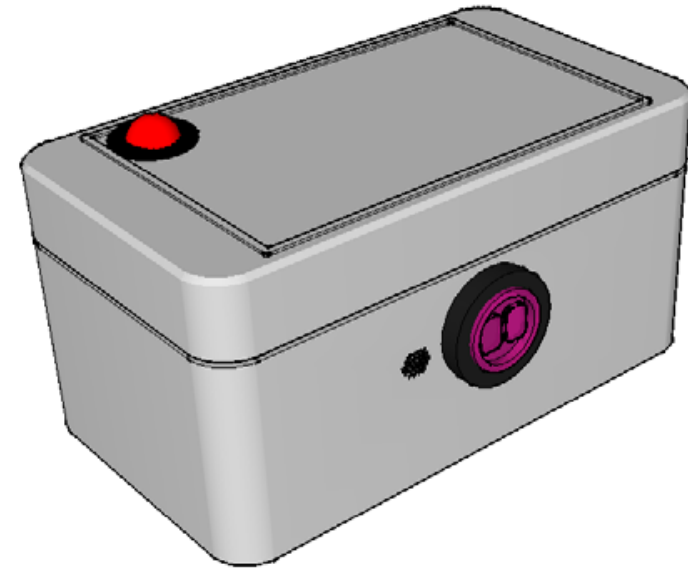

b) Kapı Ünitesi

Şekil 5. Gerçekleştirilen Çeviklik Ölçüm Sistemi

Gerçekleştirilen sistemi test edebilmek için Şekil 6'da görülen test düzeneği kullanılmıştır. Test düzeneği ana kontrol ünitesi, 5 adet kapı, yönlendirme levhası ve PC yazılımı olmak üzere 4 bileşenden oluşmaktadır. Tüm testlerde ana kontrol ünitesi ve PC yazılımı ortak kullanılmıştır. Yönlendirme levhası ve kapı sayıları uygulanan testin özelliğine göre değişstirilmiştir. 

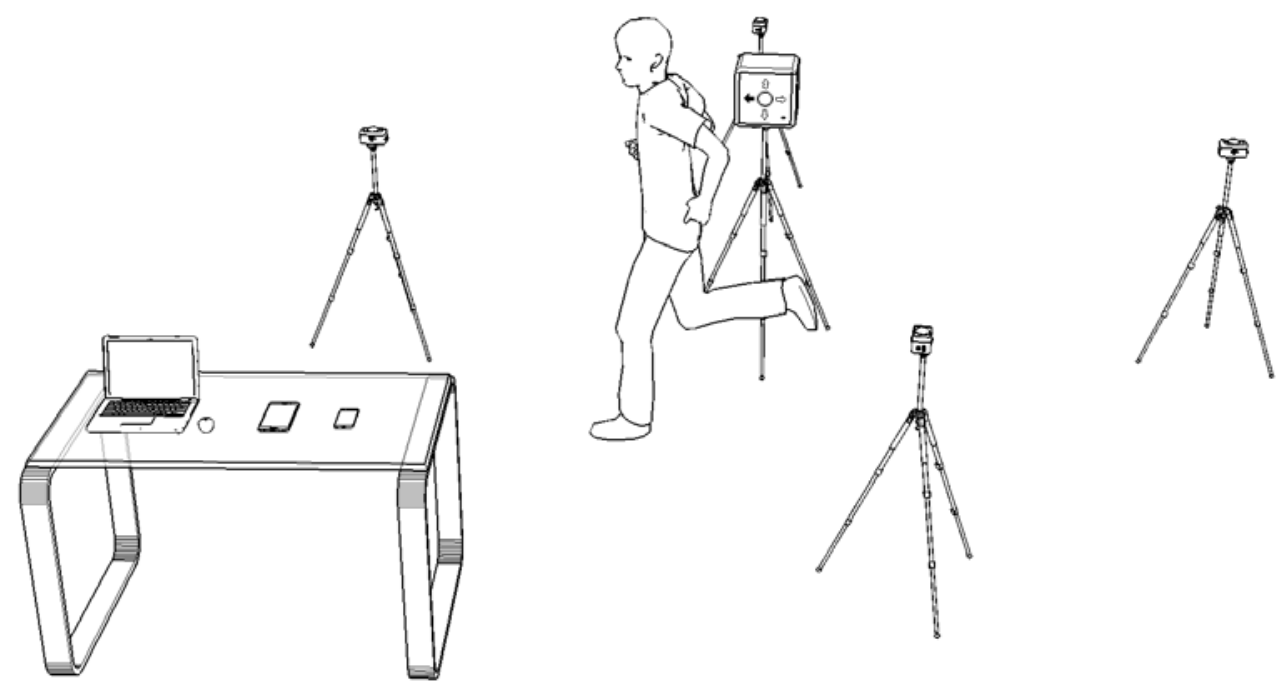

Şekil 6. Test düzeneği

\subsection{Hozlanma Testi}

5 adet kapı Şekil 7'deki saha üzerine kurulmuştur. Deneğin start kapısından geçişi ile test başlatılmış ve $5 \mathrm{~m}, 10 \mathrm{~m}, 20 \mathrm{~m}$ ve $50 \mathrm{~m}$ uzaklıktaki kapılardan geçiş süreleri ölçülmüş ve kayıt altına alınmıştır.

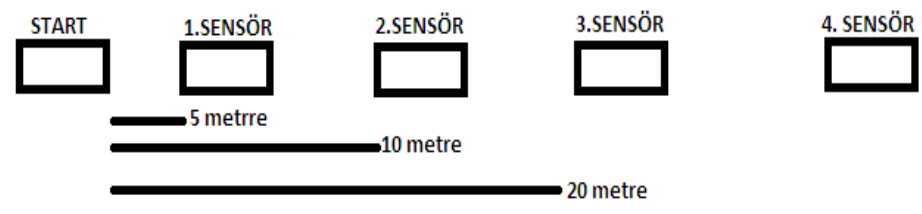

Şekil 7. Hızlanma testi parkuru

Test, hem gerçekleştirilen cihaz hem de kronometre ile eş zamanlı ölçülmüştür. Ölçüm aynı denek üzerinde 10 defa tekrarlanmıştır. Test sonucunda elde edilen veriler Tablo 3'de görülmektedir. Tablodaki ilk değer gerçekleştirilen sistem tarafından, ikinci ölçüm değeri ise kronometre ile yapılan ölçüm değerlerini göstermektedir.

Tablo 3. Hizlanma Test Sonucu

\begin{tabular}{cllll}
\multicolumn{5}{c}{ Tablo 3. Hizlanma Test Sonucu } \\
\hline Test & $\mathbf{5 m}$ & $\mathbf{1 0 m}$ & $\mathbf{2 0 m}$ & $\mathbf{5 0 m}$ \\
\hline & $1070 \mathrm{mS}$ & $2144 \mathrm{mS}$ & $4280 \mathrm{mS}$ & $10678 \mathrm{mS}$ \\
$\mathbf{1}$ & $1100 \mathrm{mS}$ & $2250 \mathrm{mS}$ & $4420 \mathrm{mS}$ & $11060 \mathrm{mS}$ \\
\hline & $1170 \mathrm{mS}$ & $2150 \mathrm{mS}$ & $4290 \mathrm{mS}$ & $10543 \mathrm{mS}$ \\
$\mathbf{2}$ & $1100 \mathrm{mS}$ & $2250 \mathrm{mS}$ & $4470 \mathrm{mS}$ & $11090 \mathrm{mS}$ \\
\hline & $1270 \mathrm{mS}$ & $2160 \mathrm{mS}$ & $4278 \mathrm{mS}$ & $10678 \mathrm{mS}$ \\
$\mathbf{3}$ & $1100 \mathrm{mS}$ & $2200 \mathrm{mS}$ & $4423 \mathrm{mS}$ & $110880 \mathrm{mS}$ \\
\hline & $1280 \mathrm{mS}$ & $2190 \mathrm{mS}$ & $4288 \mathrm{mS}$ & $10123 \mathrm{mS}$ \\
$\mathbf{4}$ & $1145 \mathrm{mS}$ & $2256 \mathrm{mS}$ & $4478 \mathrm{mS}$ & $11100 \mathrm{mS}$ \\
\hline & $1340 \mathrm{mS}$ & $2110 \mathrm{mS}$ & $4244 \mathrm{mS}$ & $10456 \mathrm{mS}$ \\
$\mathbf{5}$ & $1178 \mathrm{mS}$ & $2267 \mathrm{mS}$ & $4456 \mathrm{mS}$ & $11200 \mathrm{mS}$ \\
\hline & $1234 \mathrm{mS}$ & $2170 \mathrm{mS}$ & $4288 \mathrm{mS}$ & $10742 \mathrm{mS}$ \\
$\mathbf{6}$ & $1167 \mathrm{mS}$ & $2289 \mathrm{mS}$ & $4498 \mathrm{mS}$ & $11400 \mathrm{mS}$ \\
\hline & $2030 \mathrm{mS}$ & $2176 \mathrm{mS}$ & $4276 \mathrm{mS}$ & $10789 \mathrm{mS}$ \\
$\mathbf{7}$ & $2100 \mathrm{mS}$ & $2214 \mathrm{mS}$ & $4423 \mathrm{mS}$ & $11600 \mathrm{mS}$ \\
\hline & $1870 \mathrm{mS}$ & $2123 \mathrm{mS}$ & $4278 \mathrm{mS}$ & $10777 \mathrm{mS}$ \\
$\mathbf{8}$ & $1800 \mathrm{mS}$ & $2256 \mathrm{mS}$ & $4456 \mathrm{mS}$ & $12000 \mathrm{mS}$ \\
\hline & $1570 \mathrm{mS}$ & $2345 \mathrm{mS}$ & $4300 \mathrm{mS}$ & $10745 \mathrm{mS}$ \\
$\mathbf{9}$ & $1600 \mathrm{mS}$ & $2267 \mathrm{mS}$ & $4500 \mathrm{mS}$ & $11900 \mathrm{mS}$ \\
\hline & $1670 \mathrm{mS}$ & $2156 \mathrm{mS}$ & $4280 \mathrm{mS}$ & $10712 \mathrm{mS}$ \\
$\mathbf{1 0}$ & $1700 \mathrm{mS}$ & $2289 \mathrm{mS}$ & $47560 \mathrm{mS}$ & $11500 \mathrm{mS}$ \\
\hline & & & &
\end{tabular}


Tablo 3'deki hızlanma testinin kronometre ve ölçüm cihazı arasında ölçümler arasında 0,85 korelasyona sahip olduğu görülmektedir. Elde edilen verilerin ortalama değerleri alındığında deneğin hızlanma değeri 5m için 1405ms 10m için 2172ms 20m için 4323ms ve 50m için 11786 ms olduğu belirlenmiştir. Bu sonuçlara göre deneğin hızlanma değerinin mesafe arttıkça düştüğü görülmektedir.

\subsection{Reaksiyon Testi}

Reaksiyon testi, yönlendirme levhası ve 5 kapı olmak üzere Şekil 6'da görülen test düzeneği şeklinde kurulmuştur. Testimizde kapılar sırayla start, ileri, geri, sağa, sola olmak üzere 5 adettir. Start kapısı ölçmeğe başlanacağı anı belirtmek için kullanılır. Deneğe önceden hangi yönde hareket etmesi gerektiği söylenir. Ana kontrol ünitesi tarafından uyarı işareti yönlendirme levhasına verilir ve zamanlayıcı çalışır. Denek belirlenen yöndeki kapıdan geçip tekrardan başlangıç noktasına gelmesi arasında geçen süre ölçülür. Bu işlem her yön için tekrarlanır. Deneğe bu test 10 defa farklı zaman dilimlerinde uygulanmış ve elde edilen ölçümler Tablo 4'de verilmiştir. Tablodaki ilk değer gerçekleştirilen sistem tarafından, ikinci ölçüm değeri ise kronometre ile yapılan ölçüm değerlerini göstermektedir. Sporcunun hangi yönleri takip edeceği testi uygulayan kişi tarafından seçilir. Bu seçim sırasıyla sol,sağ,ileri,geri olarak seçilmiştir.

Tablo 4. Reaksiyon Testi Sonucu

\begin{tabular}{lllll}
\hline Test & Sol & Să̆ & İeri & Geri \\
\hline & $6520 \mathrm{~ms}$ & $6870 \mathrm{~ms}$ & $7234 \mathrm{~ms}$ & $5920 \mathrm{~ms}$ \\
$\mathbf{1}$ & $6440 \mathrm{~ms}$ & $6765 \mathrm{~ms}$ & $7025 \mathrm{~ms}$ & $5867 \mathrm{~ms}$ \\
\hline & $6225 \mathrm{~ms}$ & $6725 \mathrm{~ms}$ & $7245 \mathrm{~ms}$ & $6432 \mathrm{~ms}$ \\
$\mathbf{2}$ & $5978 \mathrm{~ms}$ & $6587 \mathrm{~ms}$ & $7012 \mathrm{~ms}$ & $6235 \mathrm{~ms}$ \\
\hline & $5897 \mathrm{~ms}$ & $7690 \mathrm{~ms}$ & $7543 \mathrm{~ms}$ & $5907 \mathrm{~ms}$ \\
$\mathbf{3}$ & $5768 \mathrm{~ms}$ & $7465 \mathrm{~ms}$ & $7389 \mathrm{~ms}$ & $5790 \mathrm{~ms}$ \\
\hline & $6789 \mathrm{~ms}$ & $7653 \mathrm{~ms}$ & $8765 \mathrm{~ms}$ & $6789 \mathrm{~ms}$ \\
$\mathbf{4}$ & $6525 \mathrm{~ms}$ & $7490 \mathrm{~ms}$ & $8586 \mathrm{~ms}$ & $6523 \mathrm{~ms}$ \\
\hline & $5980 \mathrm{~ms}$ & $8210 \mathrm{~ms}$ & $9700 \mathrm{~ms}$ & $5976 \mathrm{~ms}$ \\
$\mathbf{5}$ & $5780 \mathrm{~ms}$ & $8015 \mathrm{~ms}$ & $9456 \mathrm{~ms}$ & $5700 \mathrm{~ms}$ \\
\hline & $7890 \mathrm{~ms}$ & $8734 \mathrm{~ms}$ & $8753 \mathrm{~ms}$ & $8654 \mathrm{~ms}$ \\
$\mathbf{6}$ & $7645 \mathrm{~ms}$ & $8567 \mathrm{~ms}$ & $8587 \mathrm{~ms}$ & $8470 \mathrm{~ms}$ \\
\hline & $6345 \mathrm{~ms}$ & $6789 \mathrm{~ms}$ & $8712 \mathrm{~ms}$ & $8612 \mathrm{~ms}$ \\
$\mathbf{7}$ & $6125 \mathrm{~ms}$ & $6524 \mathrm{~ms}$ & $8523 \mathrm{~ms}$ & $8456 \mathrm{~ms}$ \\
\hline & $7981 \mathrm{~ms}$ & $8345 \mathrm{~ms}$ & $8901 \mathrm{~ms}$ & $9856 \mathrm{~ms}$ \\
$\mathbf{8}$ & $7790 \mathrm{~ms}$ & $8126 \mathrm{~ms}$ & $8756 \mathrm{~ms}$ & $9678 \mathrm{~ms}$ \\
\hline & $6790 \mathrm{~ms}$ & $7890 \mathrm{~ms}$ & $8876 \mathrm{~ms}$ & $8790 \mathrm{~ms}$ \\
$\mathbf{9}$ & $6567 \mathrm{~ms}$ & $7723 \mathrm{~ms}$ & $8670 \mathrm{~ms}$ & $8570 \mathrm{~ms}$ \\
\hline & $7589 \mathrm{~ms}$ & $7678 \mathrm{~ms}$ & $8698 \mathrm{~ms}$ & $8456 \mathrm{~ms}$ \\
$\mathbf{1 0}$ & $7235 \mathrm{~ms}$ & $7486 \mathrm{~ms}$ & $8435 \mathrm{~ms}$ & $8257 \mathrm{~ms}$ \\
\hline & & & &
\end{tabular}

Tablo 4'deki reaksiyon testinin kronometre ve ölçüm cihazı arasında ölçümler arasında 0,76 korelasyona sahip olduğu görülmektedir. Elde edilen verilerin ortalama değerlerine göre deneğin reaksiyon zamanı ileri yönde $8442 \mathrm{~ms}$, geri yönde $7539 \mathrm{~ms}$, să̆ $6800 \mathrm{~ms}$ ve sol $7658 \mathrm{~ms}$ olarak belirlenmiştir. Bu sonuçlara göre deneğin ileri ve sağa doğru reaksiyon zamanının geri ve sol yöne daha kısa olduğu görülmektedir. Deneğin sağ kol ve ayağını aktif olarak kullanması ile test sonuçları arasında uyum olduğu görülmektedir. 
Fidan U., Yıldız M., User MA.

3.3

\section{Çeviklik Testi}

Çeviklik testi, yönlendirme levhası ve 5 kapı olmak üzere Şekil 6'de görülen test düzeneği şeklinde kurulmuştur. Denek orta kapıdaki yönlendirme levhasına bakar. Ana kontrol ünitesi tarafindan rastgele yön belirlenir. Deneğin belirlenen yöndeki kapıdan geçip tekrardan başlangıç noktasına gelmesi ölçülür. Bu işlem her yön için 4 yön değiştirme sağlanarak tamamlanmıştır. Deneğe bu test 3 defa farklı zaman dilimlerinde uygulanmış ve elde edilen ölçümler Tablo 5'de verilmiştir. Tablodaki ilk değer gerçekleştirilen sistem tarafindan, ikinci ölçüm değeri ise kronometre ile yapılan ölçümlerin aritmetik ortalama değerlerini göstermektedir.

Tablo 5. Çeviklik Testi Sonucu

\begin{tabular}{llll}
\hline Sol & Săg & İleri & Geri \\
\hline $6510 \mathrm{~ms}$ & $6180 \mathrm{~ms}$ & $5810 \mathrm{~ms}$ & $7850 \mathrm{~ms}$ \\
$6400 \mathrm{~ms}$ & $6000 \mathrm{~ms}$ & $5700 \mathrm{~ms}$ & $7350 \mathrm{~ms}$ \\
\hline $6790 \mathrm{~ms}$ & $6700 \mathrm{~ms}$ & $8900 \mathrm{~ms}$ & $6510 \mathrm{~ms}$ \\
$6700 \mathrm{~ms}$ & $6650 \mathrm{~ms}$ & $8755 \mathrm{~ms}$ & $6450 \mathrm{~ms}$ \\
\hline $7100 \mathrm{~ms}$ & $7810 \mathrm{~ms}$ & $5903 \mathrm{~ms}$ & $6920 \mathrm{~ms}$ \\
$6950 \mathrm{~ms}$ & $7700 \mathrm{~ms}$ & $5850 \mathrm{~ms}$ & $6750 \mathrm{~ms}$ \\
\hline
\end{tabular}

Tablo 5'deki çeviklik testinin kronometre ve ölçüm cihazı arasında ölçümler arasında 0,65 korelasyona sahip olduğu görülmektedir. Korelasyon değeri yüksek çıkmakla birlikte yön değiştirmelerde belirgin bir düzen yakalanamamışıtır. Bu durum çeviklik testinin deneğin sadece fiziksel hazır bulunurluk seviyesini değil aynı zamanda bilişsel durumunu da ölçtüğünü ortaya koymaktadır.

\section{Sonuç}

Yapılan bu çalışma ile mevcut çeviklik ölçüm cihazlarından farklı olarak telemetri sistemi ile kablolamanın önüne geçilmiş ve yön değiştirme sayısı da 2 katına çıkarılmıştır. Ayrıca çok sık arıza yapan sıçrama matları yerine optik yansımadan yararlanarak daha kullanışlı bir ölçüm sistemi oluşturulmuştur. Sistemin doğrulama test sonuçları başarılı gözükmekle birlikte test sırasında görsel algılama ve kronometreye basma hızında hata payı olabileceği değerlendirilmelidir. Bundan dolayı çalışmanın devamında altın standart olarak kabul edilen görüntü analizleri ile yapılmalıdır. Bu çalışma, taşınabilir çeviklik ölçüm sisteminin tasarımı ve gerçekleştirilmesi odaklanılmıştır. Çalışmanın devamında belirli bir spor dalı ve sporcu grubu seçilerek çevikliklerin belirlenmesi ve antrenman programlarının sporcunun gelişimine katkısı üzerine çalışılacaktır.

\section{Kaynaklar}

[1] Karacabey, K. (2013). Sporda performans ve çeviklik testleri. International Journal of Human Sciences, 10(1), 1693-1704.

[2] Barnes, J. L.,Schilling, B. K., Falvo, M.J., Weiss, L.W., Creasy, A. K. 2007. “ vs.. relationship of jumping and agility performance in female volleyball athletes", Journal of Strength and Conditioning Research 21(4), 1192-6.

[3] Young, B.W., Willey, B. 2010. “Analysis of a reactive agility field test”, Journal of Science and Medicine in Sport, 13(3), 376-378

[4] Farrow, D., Young, W., Bruce, L. 2005. "The development of a test of reactive agility for netball: A new methodology”, Journal of Science and Medicine in Sport, 8(1), 52-60. 
[5] Young, W. B., James, R., Montgomery, I. (2002). Is muscle power related to running speed with changes of direction? Journal Of Sports Medicine And Physical Fitness, 43, 282-8.

[6] Olıver, J., Meyers, R. W. 2009. "'Reliability and generality of measures of acceleration, planned agility, and reactive agility’, International Journal of Sports Physiology Performance, 4, 345354

[7] Serpell, B. G., Young, W. B., Ford, M. 2011. "Are the perceptual and decision-making components of agility trainable? A preliminary investigation', The Journal of Strength and Conditioning Research, 25(5), 1240

[8] Jeffreys, I.A. 2011. “Task-BasedApproachto DevelopingContext-SpecificAgility”, Strength And Conditionıng Journal, 3(4), 1524-1602

[9] Hertel, J., Denegar, C.R., Johnson, P.D., Hale, S.A., Buckley, W.E. 1999. “'Reliability of the Cybex Reactor in the Assessment of an Agility Task', Journal of Sport Rehabilitation, 8, 24-31.

[10] Lima, E. W., Tortoza, C., Rosa, L.C.L., Lopes-Martins, R.A.B., 2004. "'Study of the correlation between the velocity of motor reaction and blood lactate in different times of combat in judo’’ Rev Bras Med Esporte 10(5),344-48

[11] Oliver, J., Meyers, R. W. 2009. "Reliabilityandgenerality of measures of acceleration, plannedagility, andreactiveagility”, International Journal of Sports PhysiologyPerformance, 4, 345-354

[12] Young, W., Farrow, D., Pyne, D., McGregor, W., Handke, T. 2011. “Validity and reliability of agility tests in junior Australian football players”, J Strength Cond Res., 25(12), 3399-3403.

[13] Serpell, B.G., Ford, M., Young, W.B. 2010. “'The development of a new test of agility for rugby league’, J Strength Cond Res, 24(12), 3270-3277.

[14] Gabbett, TJ, Kelly, JN, andSheppard, JM. 2008, "Speed, change of directionspeed, andreactiveagility of rugby leagueplayers.’’ J StrengthCondRes 22: 174-181

[15] Shepard, J.M., Young, W.B., (2006). Agility literature review: Classifications, training and testing. Journal Of Sport Sciences, 24:0-919-932

[16] Renkli kurt, T. (1991). Futbol Kondisyon El Kitabı. T.F.F: Eğitim Yayınları, 8.

[17] Tamer K (2000).Sporda fiziksel-fizyolojik performansın ölçülmesi ve değerlendirilmesi Bağırgan yayınevi-Ankara, sayfa: 27-154.

[18] Young, W., Farrow, D., (2006). A Review of agility: Practical applications for strength and conditioning. Strength And Conditioning Journal, 28, 24-29.

[19] Asci Alper (2013) Çocuklarda çeviklik antrenmanı HÜ Spor Bilimleri ve Teknolojisi Yüksekokulu(internet erişimi) 